\title{
A CRISE DO PLANEJAMENTO ${ }^{1}$
}

Vicente de Paula Faleiros ${ }^{2}$

\section{RESUMO}

Este artigo trata das propostas e do processo de planejamento socioeconômico, considerando que o mesmo não constitui uma técnica neutra mas uma arena de conflitos entre técnicos e políticos, Sociedade e Estado, acumulação de capital e legitimação política. Analisa a diversidade de formas de planejamento nos contextos históricos do capitalismo e a relação entre estratégia, democracia e poder centralizador no planejamento. Conclui que a chamada racionalidade da planificação e a relação entre estratégia e democracia estão articuladas à relação de forças sociais e ao contexto político.

PALAVRAS-CHAVE: Planejamento Socioeconômico, Estratégia, Democracia, Poder Político

O planejamento foi considerado na segunda metade do século XX como um marco político de organização da intervenção do Estado, opondo-se, então, o planejamento central existente no âmbito das repúblicas socialistas ao chamado planejamento democrático nas sociedades capitalistas. Em 1959 é publicado pela Fundação Getúlio Vargas - FGV o livro de John Friedmann (1959), denominado de "Introdução ao Planejamento Democrático", que resultou de um curso ministrado em 1955 em Belém, evidenciando a questão da democracia.

Seja do ponto de vista autoritário, seja na órbita democrática, a fundamentação das propostas de planejamento era de se introduzir a racionalidade na

\footnotetext{
1 Este artigo é uma versão do Capítulo 3 inserido em FALEIROS, V.P. et al. Que é o PED Planejamento Estratégico Democrático. Brasília, Instituto de Recursos Humanos - IDR/SEA/GDF, 1998, p. 39-60.

${ }^{2}$ Vicente de Paula Faleiros é assistente social, $\mathrm{PhD}$ em Sociologia, Professor Emérito da UnB e professor da Universidade Católica de Brasília.

Revista Serviço Social \& Saúde. UNICAMP Campinas, v. IX, n. 9, Jul. 2010
} 
ação pública, ou seja a capacidade de organizar as ações de forma integrada para se alcançar objetivos projetados a partir de um diagnóstico da situação presente. Friedmann (1959, p. 175) menciona a necessidade de se dominar as apropriadas técnicas de pensamento para "se abordar o estudo e a formação do comportamento". Tratava-se da formulação de um método de raciocínio para se interferir na vida em sociedade.

Essa lógica foi usada tanto no âmbito do Estado, como nas operações profissionais, dentre as quais se evidencia o Serviço Social e a Economia. Na economia trabalhava-se com a construção lógica de projetos (BATTERSBY, 1967). Alguns autores de Serviço Social como Ander-Egg (1982), Dantas (1978), Lima (1974) usaram dessa lógica do planejamento para propor uma metodologia para o Serviço Social.

No contexto dos anos sessenta, tanto em países de capitalismo dominante como a França como em países periféricos como o Brasil a questão de planejamento implica um debate acirrado entre economia, política e tecnocracia. Enquanto a tecnocracia visa a racionalidade, os políticos buscam a legitimação do poder dominante com a proposta desenvolvimentista de acelerar o crescimento e a acumulação de riquezas por meio de ações coordenadas por grandes e micro-projetos. A CEPAL Comissão Econômica para a América Latina - impulsiona esse tipo de ação, assumida no Brasil pelo Plano de Metas de Juscelino Kubistchek e pelo Plano de Celso Furtado. Em 1967, Mautner publica um livro articulando o planejamento ao orçamento governamental, usando-se o processo de planificação para ordenação das despesas conforme programas, metas e prioridades, o que reflete uma aliança da tecnocracia com o poder político pois permite articular a distribuição e controle das verbas públicas com as prioridades políticas. Isto permite também certo controle social, menos opacidade dos dados, embora a agenda oculta dos gastos ainda camufle destinações secretas e arranjos 
de gastos. Essa prática da programação de gastos é aceita mundialmente como forma de "racionalidade" que não se opõe à democracia do voto instituída.

A discussão da democracia no planejamento assume um caráter mais profundo ao se questionar o planejamento normativo e ao se defender o planejamento estratégico, principalmente depois da contribuição de Carlos Matus considerando a estratégia com a arte de lidar com as incertezas (1996, p. 11).

A dimensão estratégica do planejamento foi sendo assumida pela gestão pública a partir das experiências das guerras e das multinacionais que visavam reduzir as ameaças valorizando-se os pontos fortes e agindo sobre os pontos frágeis próprios e dos concorrentes.

Nessa perspectiva, no século XXI o planejamento assume essa visão dupla: por um lado como programação de orçamento, como receitas e despesas e, por outro, como uma ação estratégica que busca impacto, eficácia e eficiência. Para Cohen e Franco (2007, p. 121) o mercado adota estratégias em função do lucro e "nos programas sociais, o impacto ocupa o lugar do lucro", pela mudança que provoca na população destinatária. Para isso constroem-se indicadores, metas, resultados esperados, monitoramento, não se deixando de ordenar as ações por "uma matriz lógica" com fluxos e nós a serem desatados. A gestão passa a ser uma forma de ação estratégica para alocação de recursos e ação política como acontece atualmente no governo federal com o PAC - Programa de Aceleração do Crescimento que congrega vários projetos de impacto na sociedade e na propaganda política.

A seguir discutimos essa relação entre democracia e estratégia no processo de planejamento, levantando a questão da possibilidade de um planejamento que seja o avesso do autoritarismo, do voluntarismo, do individualismo, da pretensão de verdade depositada num grupo técnico, e ao mesmo tempo, seja interativo, participativo e 
crítico. Este paradigma de planejamento se coloca em ruptura com uma visão de neutralidade e tecnicismo. Esta confrontação paradigmática reflete tipos ideais: de um lado o planejamento autoritário, e de outro, o planejamento democrático. Assim definidos idealmente, esses tipos aparecem "desistoricizados", retirados do contexto histórico, onde, realmente, se desenvolve um processo complexo de rupturas e continuidades em conjunturas, as mais diversas. Para isso vamos situar historicamente esse processo de transição paradigmática na concepção de planejamento, contextualizando o PED - Planejamento Estratégico Democrático - nessas rupturas e continuidades. O PED é uma proposta formulada Ademar Kyotoshi Sato a partir da elaboração de Carlos Matus e que foi posta em prática no Governo Popular do PT de 1994-1998 no Distrito Federal. A pesquisa de Faleiros (1998) e a dissertação de mestrado de Capitani (2002) dão conta dessa proposta e dessa experiência num contexto histórico de democratização da sociedade brasileira pós Constituição democrática de 1988 que consolidou legalmente o processo de transição da ditadura para a democracia no Brasil. A transição democrática mudou a forma de intervenção do Estado. Como assinala Ianni (1977) “diferentes políticas econômicas governamentais provocaram a expansão de estruturas político-administrativas do País" e na esfera políticoadministrativa estava em curso a divisão social do trabalho, devido à crescente diferenciação interna da sociedade brasileira (p. 313). Acrescenta que houve uma transição do clientelismo para o princípio do mérito que caracteriza o Estado burguês. Nessa perspectiva o planejamento buscava articular o Estado ao processo moderno de acumulação de capital com técnicas que propiciassem a produtividade. A chamada racionalidade do planejamento acima mencionada é construída em função dessa produtividade com articulação dos chamados "fatores de produção". Paradigmas de continuidades e rupturas no planejamento são processos inseridos numa determinada 
forma de produção e de correlação de forças, em momentos históricos e conjunturas de desenvolvimento do processo de acumulação de capital e organização empresarial, de regulação do Estado e estruturação do saber científico e técnico.

Sem querer esgotar a temática, assinalamos quatro momentos desse processo, destacando, em especial, as formas de administração da produção. A produção é o processo-chave de organização das relações sociais não só quanto à direção e propriedade dos meios de produção, mas na estruturação da vida quotidiana como compras (consumo), horários (rotinas), transporte (fluxos), folgas (lazer), acesso à moradia, além de co-determinar o acesso à educação (pública/ privada), à saúde (planos de saúde, localização) e aos serviços estatais. Esta produção está presente nas formas estatais, além de se relacionar com o Estado regulador, político e consumidor. Esta articulação dos meios e relações de produção com os meios e relações de vida cotidiana, implicam o imaginário, a cultura, os símbolos que não se reduzem ao mundo produtivo e nele também influem, articulando-se estrutura e superestrutura.

\section{O TAYLORISMO E O PODER DO CAPITAL}

Para pensar estas mudanças e continuidades no processo de planejamento distinguimos, em primeiro lugar, o momento taylorista e fordista, aliado ao keynesianismo que representou uma ruptura com a produção fragmentada, em partes subcontratadas, e consolidou um poder gerencial dominante sobre os trabalhadores. A guerra agudizou a necessidade de coordenação das ações por programas, centralizando decisões, o que já vinha sendo praticado no âmbito soviético, dando continuidade e ampliando o taylorismo e o poder técnico.

Em relação ao taylorismo-fordismo destacamos da entrevista com Sato (1998) que: 
'a maioria dos servidores públicos é prisioneiro de sistemas arcaicos caudatários do taylorismo das linhas de montagem do processo industrial fordista concebido para que um pequeno número de pessoas instruídas e informadas exercesse comando sobre outros instruídos e desinformados'. Continua: 'o servidor público que participar da contemporaneidade que exige instituições públicas flexíveis e adaptáveis que responda rapidamente às necessidades da população, oferecendo bens e serviços de alta qualidade e que, ao mesmo tempo, confia poder aos Cidadãos ao invés de simplesmente servi-los' (SATO, A Ética do Planejamento Estratégico, IDR, s/d).

O taylorismo ${ }^{3}$ e o fordismo mudaram a forma de produção capitalista fragmentada para a produção em série, com a correia de transmissão em cadeia, com um planejamento sistemático do processo de trabalho para adaptação do homem a esse processo, traduzindo, ao mesmo tempo, a exigência capitalista de produtividade e de controle global de unidades diversificadas e a expropriação do saber prático dos trabalhadores para concentrá-lo em mãos de técnicos superiores. Taylor e Fayol consolidam a separação entre decisão e execução, entre o poder de ordenar e a prática do executar e sob a égide da "organização científica do trabalho".

Já no final do século XIX os capitalistas americanos começaram a colocar a produção sob o comando do taylorismo, diante da resistência e sindicalização dos trabalhadores e da luta pelas oito horas diárias de trabalho. A introdução do taylorismo, diz Heloani (1994, p. 15), “acelerou o projeto capitalista de por fim à influência dos trabalhadores de ofício". Taylor busca legitimar o aumento da produtividade com o

\footnotetext{
3 Frederick Winslow Taylor viveu de 1856 a 1915. Era engenheiro e dedicou-se ao estudo da "organização racional" do trabalho com o estudo de uma normatização dos tempos e movimentos do trabalhador e da máquina, propondo o pagamento pelo desempenho do trabalhador para aumentar sua produtividade.
} 
discurso da prosperidade do empregado, o que foi assimilado por Ford ao fazer de seus trabalhadores compradores dos produtos que fabricavam, num processo de constante aumento da produção. O planejamento da produção é, pois, uma expropriação duplamente articulada: a do tempo do trabalhador e a de seu movimento (tempos e movimentos) que passam a ser controlados pelo poder dos técnicos, separando o trabalho manual do trabalho intelectual. Ao trabalho intelectual correspondem o planejamento, a administração, o controle dos tempos e movimentos. A produção deve ser, assim, dividida e especializada, assinalando Heloani (1994, p. 19) que Taylor busca fazer com que este saber seja apropriado pela organização. O trabalhador que falha no processo de produção deve ser treinado individualmente para o melhor desempenho por instrutores devidamente treinados.

O taylorismo representa, assim, o protótipo de um sistema autoritário e individualista de planejamento, usando a "ambição" ou a subjetividade do trabalhador para inseri-lo nesse processo. Segundo o autor citado, o departamento de planejamento é que "vai acumular o saber sobre o desempenho dos trabalhadores e buscar o modo mais adequado de organizar insumos para a produção. Para tanto, realiza estudos de como determinar 'cientificamente' o ritmo e as tarefas que cada indivíduo pode suportar" (HELOANI, p. 25). É a direção, segundo Taylor, que deve elaborar normas para a padronização das atividades com a conseqüente implementação da inspeção do processo e do produto.

O modelo taylorista vai influenciar a experiência soviética. Lênin, apud Heloani (1994, p. 37), elogia “o progresso da ciência” que Taylor representa no sentido de aumentar a produtividade do trabalho humano, acentuando-se, nas condições da "economia de guerra" a centralização das decisões e a disciplina do trabalho. Esta tendência, acentuada pelo estalinismo, freou o movimento do poder dos sovietes ou 
conselhos populares. Através do plano central controlava-se todos os planos setoriais, num sistema determinado por metas de produção e decisões que vinham de cima para baixo. Esta centralização exacerbada trazia uma combinação de autoritarismo e voluntarismo pois as metas eram impostas por órgãos centrais aos regionais e setoriais.

\section{O PÓS-GUERRA E O CONTROLE INTEGRADO DA EFICIÊNCIA}

A Segunda Guerra Mundial, mesmo com a forte presença das forças soviéticas, abriu caminhos à expansão capitalista no mundo e à integração multinacional de companhias privadas e ações estatais que exigiam um planejamento estratégico rigoroso para derrotar o inimigo com ações comuns dos aliados, obrigados, pelas circunstâncias a atuar juntos apesar das diferenças de língua, cultura, formação militar, condições físicas. A reconstrução das economias, incluindo o Plano Marshall na Europa, trouxe a expansão das multinacionais, com exigências de produção integradas em nível mundial, e ao mesmo tempo, em lugares diversificados. As comunicações tiveram um boom extraordinário no bojo da necessidade de interação entre lugares e atores tão diversos, aperfeiçoando-se o telégrafo. Novo boom viria mais tarde com os satélites.

Nesse contexto, o planejamento adquiriu importância fundamental no âmbito das empresas e dos governos. A necessidade de se projetar a mudança para o futuro passou a ser crucial, e, mesmo, definitória do plano, segundo Ozbekhan (1969). Novick (1969) assinala, entretanto, que há grandes diferenças de fundo e de forma de um plano a outro, segundo a natureza da organização, a amplitude do plano e o quadro temporal ao qual se aplica (p. 243). Tanto as empresas privadas como os governos passaram a buscar mais eficiência, ou seja menos custos e mais resultados com os recursos 
disponíveis. Nos Estados Unidos, no âmbito governamental Novick implanta o $\mathrm{PPB}^{4}$ (Plano-Programa-Orçamento ou Orçamento por Programas) para resolver o problema da afetação de recursos no plano, a partir das decisões tecnocráticas, influenciadas pelo desenvolvimento do cabedal científico e da informação. A partir de 1947 (HAMBURGUER, 1976) foi implementado o Council of Economic Advisors com relatórios estatísticos econômicos mensais. Desde 1952 a ONU publicava o World Social Situation, iniciando o processo de construção de indicadores sociais ou da informação para o planejamento.

O controle da informação e sua centralização nas mãos de um grupo depositário do saber aumentou e consolidou o poder técnico e normativo que, assim, pode projetar para o futuro tendências do passado. Pelas novas técnicas de informação pode-se conhecer melhor o passado e o presente, e os recursos puderam ser melhor controlados e com previsão de "entradas e saídas", ou seja planejar implicava conhecer, prever, alocar e gerir recursos.

A alocação de recursos pessoais e financeiros foi feita a partir da definição da missão da organização e de seus objetivos, do conjunto de atividades necessárias para realizá-los (programas), dos recursos e da utilidade de cada programa (effectiveness), integrando o plano na cultura organizacional, controlando-se não só recursos mas a organização como um todo. No âmbito da administração pública esta mudança foi um passo fundamental para pensá-la em termos de objetivos, o que permite a escolha de caminhos alternativos, ou seja, o futuro também poderia ser diferente do passado, alternativo, mas não alterativo, pois não se questionava as relações de poder. Novick diz que "a planificação é o fato de produzir uma série de possibilidades significativas de escolher linhas de ação, graças ao exame de soluções alternativas” (1969, p. 254). A

\footnotetext{
${ }^{4}$ O PPB foi implantado no Departamento de Defesa (ligado à guerra) dos Estados Unidos desde 1960. Revista Serviço Social \& Saúde. UNICAMP Campinas, v. IX, n. 9, Jul. 2010
} 
escolha entre várias alternativas ficava nas mãos do poder centralizado no técnico e no mandante ou no bloco dominante para prever ações e alocar recursos. Uma vez definida a alternativa buscava-se articular um sistema de convergência de esforços de cada um e de todos, como lembra o Premier Plan de Modernisation et d'Équipement de Paris de 1956, citado por Penna (1959).

Contrariamente ao plano centralizado soviético os franceses editavam, em 1966 seu $V^{o}$ Plano, denominado indicativo, pois apenas dava as grandes orientações para a economia de mercado, prevendo-se cenários para a França dos anos 70. Na introdução do documento os planejadores dizem que "o Plano é como o plano de vôo, para organizar a expansão da economia e definir as condições da repartição", ou seja articulava o processo global de acumulação de capital numa prospectiva expansionista, prevendo os grandes investimentos públicos. A elaboração do "Plano" levava quatro anos, devendo ser discutido e aprovado pelo Parlamento. Assim, o planejamento público se articula organicamente ao processo produtivo de expansão capitalista controlando o poder técnico, os recursos e a informação. Abrahão (1995) lembra que "os processos de planejamento não ocorrem em um meio vazio, desprovido de interesses, antes ocorre e é condicionado pela "trama de interesses" dos diversos "atores sociais"5 que vão procurar estabelecer fortes condicionantes para a temporalidade dos programas e projetos e impor os contornos nos quais se definirão e redefinirão todos os princípios estruturadores dos programas que se querem manter, reestruturar e implantar, desde o financiamento até a prestação de serviços e os modos de controle e execução financeira e orçamentária” (1995, p. 1).

\footnotetext{
${ }^{5}$ Sublinhado pelo autor do texto.
}

Revista Serviço Social \& Saúde. UNICAMP Campinas, v. IX, n. 9, Jul. 2010 


\section{A AMÉRICA LATINA}

A seguir vamos, brevemente, situar o desenvolvimento do planejamento no contexto econômico e político da América Latina e do Brasil.

As transformações do modelo de desenvolvimento na América Latina, do exportador para o de substituição de importações, como definiu Tavares (1979) entre 1930 e 1945 se fez nas condições bem lembradas por Ianni (1977, p. 33) de “reformulação da dependência estrutural que caracterizava o subsistema econômico brasileiro". É nesse período que se funda o DASP (Departamento Administrativo do Serviço Público) como órgão coordenador do sistema público que só paulatinamente aglutina funções de planejamento também paralelamente realizado pelos Conselhos Nacionais e pela Coordenação da Mobilização Econômica, durante a Guerra. Em 1939 formula-se um Plano Especial de Obras e Equipamentos que reunia, a posteriori, as previsões já orçadas, o que foi repetido em 1943 (POE), mas que valeu “como mudança de sinais nas práticas governamentais" (Benedicto Silva, in: FRIEDMANN,1959). Obras e equipamentos formam a infra-estrutura necessária à expansão do capital. No pós-guerra o Conselho de Economia é implantado em 1949 quando se formula o plano SALTE (Saúde, Alimentação, Transporte e Energia) sob a coordenação do DASP, mas de pouca efetividade. Em 1952 cria-se o BNDE (Banco Nacional de Desenvolvimento), sob influência do nacionalismo e da CEPAL, para financiamentos de longo prazo ao processo de investimentos ou acumulação capitalista, com o envolvimento do Poder Legislativo. O governo de Juscelino Kubistchek abre-se para o capital estrangeiro articulando-o a seu Programa de Metas interno, integrando o planejamento estatal ao processo global de expansão capitalista. A SUDENE (Superintendência de Desenvolvimento do Nordeste), criada em 1959, traz a marca desta proposta. 
Os governos autoritários, após o golpe de 1964, dão um caráter ainda mais tecnocrático e burocrático ao planejamento, não só excluindo a sociedade da discussão de si mesma e centralizando em Brasília as grandes decisões que sempre caminhavam de cima para baixo, mas reforçando a aliança do Estado com as multinacionais.

Enquanto que nos países desenvolvidos o processo de regulação (incluindo o planejamento) da economia é o da busca do equilíbrio interno, na América Latina a discussão central é relativa ao desequilíbrio externo. É na CEPAL, fundada em 1949, que se forja o núcleo difusor do processo de planejamento técnico na América Latina no pós-guerra. A CEPAL, no intuito de superar o subdesenvolvimento, no entanto, aglutina, naquele momento, um pensamento crítico sobre a desigualdade regional, mas, contraditoriamente, considera o planejamento como técnica neutra. Ianni (1977, p. 145) cita um relatório do Grupo Misto BNDE/CEPAL que diz: "o primeiro ato de neutralidade da técnica de programação consiste em discutir as possíveis taxas de crescimento e decidir se deve recorrer ou não ao capital estrangeiro [...]”. A neutralidade da técnica parece não contrariar o pensamento crítico. Lotero (1988) enfatiza o pensamento crítico da CEPAL quando esta analisa a desigualdade do sistema mundial, a deterioração dos termos de intercâmbio e a dinâmica do centro que induz o desenvolvimento da periferia. $\mathrm{O}$ discurso da neutralidade técnica permitia o trânsito e a aceitação da CEPAL por vários tipos de governo, ao mesmo tempo em que defendia a acumulação de uma poupança nacional, a contribuição do capital estrangeiro para esta poupança, a industrialização dos países da periferia, a reforma agrária, uma política ativa de empregos, uma política redistributiva de rendas, a substituição de importações, quando a renda por habitante cresce mais que a capacidade para importar. Ou seja, sob a capa da neutralidade havia a proposta de implementação de um desenvolvimento capitalista com o papel condutor do Estado, sendo "o papel da técnica apresentar com 
objetiva imparcialidade, as distintas soluções, o que cada uma delas requer e seus prováveis efeitos" (CEPAL, 1969, p. 115). O campo de possibilidades para o saber técnico que parece cínico pois paira acima "do bem e do mal", era o da modernização na defesa da "imparcialidade" e da "maximização da racionalidade".

Como podemos observar, as concepções cepalinas não são neutras, pressupõem o papel ativo da burguesia nacional e do Estado e trazem, em seu bojo, como observa Padrão (1988, p. 86), um projeto sócio-político, que só aparentemente estaria separado do poder técnico. Em realidade, planejamento e projeto sócio-político se articulam.

\section{O POLÍTICO E O TÉCNICO. O FRACASSO DA TECNOCRACIA}

Os movimentos sociais dos anos 60 trouxeram à tona a questão da democratização nas empresas e na sociedade, enfatizando-se, por exemplo, a autogestão e a co-gestão, implementando-se o planejamento por objetivos e articulando-se o poder político ao poder técnico. A crise dos anos 70 colocou em aberto a competição internacional e desencadeou um novo processo de globalização da economia com fusões de empresas, implantação do toyotismo, privatização, desregulamentação do Estado, reengenharia e qualidade da produção com profundas conseqüências na diminuição de empregos e precarização do trabalho e dos direitos sociais, ampliando-se a presença do planejamento denominado de estratégico. Numa manifestação de contra-hegemonia é que o planejamento democrático e participativo foi deitando raízes em experiências e propostas de construção do poder popular.

A chamada racionalidade técnica só foi se revelando política à medida em que as forças políticas foram questionando o processo capitalista, atrelado à proposta de um desenvolvimento nacional conduzido pelo Estado com a chamada burguesia 
nacional. Foi a Revolução Cubana (1960) que desencadeou a alternativa de um projeto socialista para a América Latina, revelando a profunda situação de miséria da América Latina e a potencialidade de uma mudança revolucionária. O processo revolucionário se manifesta, inclusive, no pipocar das guerrilhas, questionando e opondo-se ao tipo de mudança que estava em jogo através da integração e da cooperação internacional (Carta de Punta del Este de 1961).

A racionalidade formal e normativa é questionada no núcleo central do poder técnico da CEPAL, o ILPES - Instituto Latinoamericano de Planejamento Econômico e Social. No Seminário do ILPES de 1966 busca-se, a conciliação da racionalidade formal (meios-fins) com a racionalidade substantiva, de fundo que "consiste no enfoque da problemática do conjunto da sociedade para determinação dos objetivos últimos da mesma e das mudanças requeridas para assegurar seu cumprimento" (p. 28). Considera que os planos foram feitos "com uma marcada tendência em constituí-los em meios de racionalização e coordenação formal da política de desenvolvimento" (p. 7) e faz uma crítica a essa tendência, chamando a atenção para a necessidade de os planos se tornarem operativos e instrumentos de coordenação de ações, "buscando promover os reajustes e as modificações a que deveriam dar os desvios da realidade com respeito ao programado" (p. 8), ou seja, o plano deve adaptar-se à realidade e não realidade ao plano. Já fica clara a crise do formalismo e da neutralidade. Nesse sentido, a planificação deve ser um instrumento para orientar as reformas estruturais (p.10), assumindo-se uma orientação reformista que se contrapõe à idéia de revolução. Ao invés da planificação para o desenvolvimento, propõe-se a planificação para a mudança (planificación para el cambio), entendida também como modernização de uma sociedade dual com marginalizados-atrasados (maioria) e integrados (minoria). 


\section{PLANO E PARTICIPAÇÃO POPULAR - TENTATIVA DE DEMOCRATIZAÇÃO DO PLANO}

A eleição de Salvador Allende para a Presidência do Chile em quatro de setembro de 1970, liderando uma frente de partidos de centro-esquerda, a UP - Unidad Popular - tem como proposta a implementação do poder popular, como consta do programa da UP: “As necessidades de transformação revolucionária do país somente podem ser levadas adiante se o povo chileno tomar o poder em suas mãos e exercê-lo efetivamente .6 Este poder, entretanto tem como condição o aprofundamento da democracia e das conquistas dos trabalhadores, implementando-se o governo popular, com uma nova estrutura institucional de poder. Assim o programa reza que os trabalhadores e setores organizados "serão chamados a intervir nos seus respectivos lugares nas decisões dos órgãos de poder". Não se trata, pois de um poder consultivo, mas de um poder decisório nos órgãos de poder aquele que propõe a Unidade Popular. Este programa partia da base organizacional existente para construir uma proposta popular e democrática, sofrendo as contradições desse processo. Na luta por implantar o poder popular nas fábricas havia inúmeras resistências, mas o próprio Ministro da Economia, Pedro Vuskovic, em 1971 (1972, p.112) reconhece que "a presença dos trabalhadores, com tudo que isto significa, se fortalecerá mais ainda na medida em que estenda não só às fábricas, e não só ao nível superior, através da direção geral da CUT, mas aos níveis intermédios, sejam setoriais ou regionais". O Ministro assinala que na própria "Corporación de Fomento" já existem comitês para programar as empresas da área social, por exemplo, no setor têxtil, onde os trabalhadores estão fazendo um esforço para eliminar as "irracionalidades do sistema capitalista". Esta participação dos trabalhadores se tornou efetiva em grande quantidade de empresas com

\footnotetext{
${ }^{6}$ New Chile, 1973, Edition. New York, North American Congress on Latin America, 1973, p.134.

Revista Serviço Social \& Saúde. UNICAMP Campinas, v. IX, n. 9, Jul. 2010
} 
o apoio de intelectuais, tornando-se mais organizada à medida que a direita boicotava a produção. Formaram-se os cordões industriais por bairro integrados às Juntas de Abastecimento e Preços (JAPs) que organizavam e faziam escoar a produção. O planejamento da empresa, sob orientação dos partidos Socialista e MAPU (Movimento de Ação Popular Unificado), da UP e também do MIR (Movimento de Esquerda Revolucionário) passou a ser discutido pelos próprios trabalhadores, que inclusive fabricavam peças de reposição boicotadas pelos Estados Unidos. Esta experiência marcante foi derrocada pelo golpe militar de 11 de setembro de 1973, mas mostrou a possibilidade de uma via democrática e popular de transformação da sociedade.

Carlos Matus, que fora Ministro do Planejamento da UP, publica, em 1972 o livro Estratégia y Plan onde, de certa forma, incorpora essa discussão entre o poder técnico e o poder político ao considerar que há discrepâncias entre o critério de "economicidad" ou técnico e o critério político de direção do processo de desenvolvimento, chamando também a atenção para a complexidade da planificação com elementos qualitativos e quantitativos para que se integre, cada vez mais, nos processos decisórios. Matus traz à tona a dimensão estratégica do planejamento enquanto processo formador de um consenso por parte do governo, e enquanto formador de consciência por parte da oposição ${ }^{7}$. A dimensão política, para Matus, manifesta-se na dimensão estratégica do grupo dirigente em formar consensos. A lógica de criação de consensos deve se combinar com aquela de gestão de recursos. Matus, no entanto, não incorpora a questão democrática enquanto envolvimento dos trabalhadores no processo decisório do planejamento, o que será feito pelo PED.

\footnotetext{
${ }^{7}$ Sublinhado pelo autor do texto. Para Matus "a racionalidade formal aplicada à racionalidade material dos grupos dominantes, define um modelo 'técnico e político' de comportamento, que surge de uma análise de viabilidade 'a partir' (desde, em espanhol) do poder e conforma uma 'estratégia oficial'" (p. 107).
} 
A questão democrática, entretanto, teve outro viés na sua incorporação ao planejamento, a partir da derrota do fascismo na Segunda Guerra Mundial. Desde 1955, no Brasil, John Friedmann, discutia na elite da Escola Brasileira de Administração Pública, a proposta de um planejamento democrático. Para Friedmann o planejamento "é basicamente um processo de raciocínio e de se enfrentar da maneira criadora as situações que se nos deparam" (p. 9) "devendo focalizar atenção nos agentes e na ação", mantendo-se, assim, intimamente ligado à vida e aos valores do povo, com contínua revisão e reformulação das decisões anteriormente tomadas. Chama a atenção para a existência de vários níveis de planejamento, salientando a necessidade de se coordenar esses vários níveis. Distingue o planejamento centralizado de cima para baixo (em alusão à União Soviética) dos planos que "destinam-se à informação" (p. 13), em alusão aos Estados Unidos. Assim, democracia, para ele não significa poder de decisão da base, mas informação, coordenação, transparência, flexibilidade e interação, vinculação entre fatos e valores. E acrescenta: "para ser bom, um plano tem de ser aceitável pelos políticos" (p. 30), aliando técnica e política. Em 1980 o ILPES realiza, um seminário em que se constata que a descentralização não se realizou, o desenvolvimento continuou desigual em benefício de certas regiões, setores e grupos, sem equidade, acentuando-se a necessidade de participação das diversas ordens do poder político. É o reconhecimento do fracasso do tecnocratismo também implicitamente reconhecido por Friedmann (1988) que chega à conclusão de que "o planejamento não pode ser separado da política" (p.169). Este ponto de chegada é o ponto de partida do PED que, ao se definir democrático, articula o processo de planejamento como um ato político num contexto político.

Friedmann e Matus centram, no entanto, o processo de planejamento na solução de situações-problema, dizendo o primeiro que "o problema seja limitado e 
reduzido a proporções que o tornem passível de análise" (p. 40), considerando ainda a definição do problema numa situação interativa.

A proposta de Carlos Matus, denominada PES (Planejamento Estratégico Situacional) se afirma no pressuposto mais ou menos óbvio de que o "o futuro não pode ser conhecido" (MATUS, 1997, p. 260 et seq.) e de que um plano não pode ser feito de forma determinista, concebendo-o como um jogo, que é decidido no seu desenrolar, pela interação entre os jogadores e a mudança das circunstâncias, para se tornar, finalmente, uma aposta. Deve-se, diz ele, sempre integrar o plano de ação com o plano de demandas (solicitação feitas a outros atores) e denúncias (difusão para as bases do não cumprimento das ofertas de cooperação de outros atores). Nesse sentido o PES se torna, cada vez mais, um plano político, de direção política, associado ao bloco no poder, "ao senhor presidente", articulando-se o "deve ser" com o "pode ser" nos vários momentos de uma racionalidade, articulados em momento explicativo (o que é a realidade para eles e para nós), momento normativo (dever ser), momento estratégico (pode ser) e momento tático-operacional (mediação para a ação). Para ele (1993, vol 2, p. 404), "o dilema central do dirigente está entre deve ser e não pode ser e pode ser mas não deve ser".

\section{AS FORMULAÇÕES DEMOCRÁTICAS EM ÁREAS E GRUPOS LIMITADOS}

Na esfera do planejamento central os que decidem estão articulados no bloco do poder dominante e inscritos no jogo de forças entre Legislativo e Executivo e de pressões poderosas de grupos econômico-políticos que articulam seus interesses por meio de lobbies e grupos de pressão num toma-lá-da-cá de influências, favores, implementações. 
Já num grupo mais restrito, uma alternativa popular do planejamento estratégico foi a elaboração do Método MAPP - Método Altadir de Planificación Popular (1994) para enfrentamento de questões simples de comunidades, organizações ou bairros. O ZOPP - (Ziel Orientierte Projekt Planung - ou Planificação Orientada para Projetos), também faz parte desse "sistema", segundo os formuladores do MAPP. Parte-se do pressuposto de que o sistema de planejamento requer vários métodos conforme a hierarquia e complexidade dos problemas abordados nos distintos níveis do sistema organizativo. Ou seja, não se visualiza mais a unicidade do planejamento, mas a sua pluralidade. Essa pluralidade, para o MAPP, deve estar integrada em um sistema.

Segundo os formuladores do PES, este teria a potência de planejar para o nível central diretivo público, de alta complexidade, enquanto que a proposta do MAPP é "de simplicidade e potência para enfrentar poucos problemas de baixa inter-relação e complexidade e onde predomina o processamento prático-operacional” (p. 1), considerando o ZOPP como de nível intermédio, assunto a que voltaremos mais adiante.

O MAPP se presta, segundo seus autores (FONDO EDITORIAL ALTADIR, 1994, p. 4), para discussão de problemas junto a organizações populares, desenvolvendo-se com os seguintes passos: busca da identificação de insatisfações(a), descrição de problemas (b), análise de suas causas e conseqüências (c), definição de objetivos (d), identificação de causas críticas (e), seleção e desenho de operações para atacar as causas principais dos problemas (f), definição dos recursos e orçamentação (g), identificação dos atores relevantes para geração, manutenção e enfrentamento dos problemas e sua motivação face às ações desenhadas (h), análise dos recursos críticos de poder em um problema e aplicação sumária do conceito de peso, poder e força dos atores (i), análise da trajetória ou seqüência temporal do plano (j), análise da vulnerabilidade do plano (k), avaliação do desempenho dos responsáveis pelo plano (1). 
Esses passos devem respeitar a visão que a população tem dos problemas, mas está voltado para o "problem solving", de acordo com um processo conduzido por uma equipe de técnicos. No entanto, ao invés de se politizar a ação, essa metodologia pode tecnificar uma discussão política, não distinguindo o poder dos atores na própria formulação do problema. Ao invés de se partir da decisão centralizada visa-se tomar como desencadeamento da ação "a insatisfação" popular. No sentido de se fortalecer a interação e a comunicação entre os participantes do processo há preocupação em se discutir de baixo para cima a formulação de propostas de ação, o que evidencia um viés democrático.

O método ZOPP surgiu em 1983 no processo de "cooperação internacional" de agências alemãs com países periféricos para formulação, acompanhamento e controle dos projetos elaborados nesse contexto, buscando a eficiência no acordo de objetivos entre os participantes. A primeira etapa do ZOPP é uma análise da participação dos grupos destinatários e envolvidos no projeto ou afetados por ele para, em seguida, identificarem-se e analisarem-se os problemas centrais, a relação causa-efeito e transformar a hierarquia de problemas numa hierarquia de objetivos. Depois é que se identificam as soluções alternativas. A matriz de planejamento do projeto relaciona a descrição do problema com os indicadores de objetivos (metas), dados, e as suposições do que deva ocorrer (dependentes e não-dependentes do projeto) para que se realize efetivamente o projeto nos seus resultados e atividades. Definem-se, ainda, a duração do projeto, a região que abrange, o grupo destinatário e as instituições parceiras. O controle do projeto é rigorosamente definido pelas fontes de comprovação de cada etapa. Na perspectiva do ZOPP é importante considerar os "imprevistos previstos" ou seja as condições necessárias e suficientes para a realização do projeto. 
Como se pode observar, trata-se de um processo de planejamento inserido em um contexto de "cooperação", para maximizar os recursos destinados a grupos específicos, ainda com alto poder técnico para resolver problemas.

$\mathrm{O}$ PED, ao contrário, busca desenvolver um processo coletivo e interativo para colocar os recursos na ótica dos participantes e não só dos dirigentes, no caso ZOPP, as agências internacionais de cooperação. No final deste texto apresentamos um quadro comparativo entre PES e PED em relação às dimensões definidas no primeiro capítulo (cf. FALEIROS et al., 1998). Antes, porém, vamos situar o processo de planejamento no contexto do capitalismo contemporâneo.

\section{A COMPETIÇÃO INTERNACIONAL E A REDUÇÃO DAS AMEAÇAS EXTERNAS E VALORIZAÇÃO DAS OPORTUNIDADES}

A partir da crise do final dos anos 70, marcada por profunda recessão, o capitalismo (ver FALEIROS, 1996), sob a égide da mundialização ou globalização buscou novas formas de acumulação na competição internacional, com fusões de empresas, deslocamento da produção para vários locais pelas multinacionais, com a predominância do capital financeiro mundial e da chamada flexibilização econômica. Este se desloca rapidamente em poucos segundos para ganhar com as bolsas, a desvalorização das moedas, as aplicações financeiras em qualquer lugar do mundo. Ou seja, o deslocamento dos investimentos e das aplicações financeiras se faz segundo a maior rentabilidade possível em diferentes partes do mundo e não mais em consideração a um determinado país, acentuando a competitividade internacional. Esta competição se faz graça ao avanço da rede de informações e comunicações interconectadas por satélites poderosos. Mudam também as condições de produção: os serviços se terceirizam concentrando-se a empresa numa "missão" principal em torno da qual os 
serviços periféricos são subcontratados. Este modelo de gestão vem sendo também assumido pelo Estado com o discurso das parcerias, da regionalização, da descentralização. Pressionado pela dívida pública o Estado, por sua vez, busca reduzir o déficit, seja reduzindo custos seja reduzindo o acesso a certos direitos e benefícios. Além da terceirização e da globalização, o desenvolvimento tecnológico tem levado a uma mudança significativa nas formas de produção com o uso da informática e da robótica $^{8}$, com profundas conseqüências para o extermínio de postos de trabalho. Por exemplo, num prazo de 3 anos (de 1992 a 1995) a Mercedes Benz do Brasil reduziu o número de empregados em $28 \%$ (de 17.000 para 12.200) e aumentou a produção diária de caminhões em $87 \%$ ( de 92 para 172 unidades $)^{9}$, configurando um salto significativo na produtividade e na produção e uma redução brutal de empregos. Este quadro se repete em todas as grandes e médias empresas: mais produção com menos emprego, aliado à mercerização, à flexibilização e à importação. Na crise de 2009 a redução de postos de trabalho pode atingir 50 milhões de trabalhadores no mundo.

Os trabalhos permanentes se tornam temporários e precários ${ }^{10}$ e os salários ficam comprimidos. Um exemplo pode ser o da citada revista Veja que assinala que os calçadistas de Franca (SP-Brasil) hoje fazem em casa, com um salário menor, sem garantias, e com a família, inclusive crianças, trabalhos que antes faziam na fábrica com as garantias previdenciárias e para o mesmo patrão. Tanto empresas privadas como os governos que demitem costumam recontratar alguns trabalhadores em novas condições, por exemplo substituindo trabalhos permanentes por temporários e com salários mais baixos.

\footnotetext{
${ }^{8}$ A montagem do carro Chevette era toda manual, enquanto que o Gol e o Corsa implicam 270 pontos simultâneos de solda em apenas parte da carroceria, o que só pode ser feito pelo uso de robôs (Veja, $04 / 10 / 95$, p. 35).

${ }^{9}$ Veja, 4/10/95, p. 35.

${ }^{10}$ Castel (1995) fala de esfacelamento (effritement) do sistema de assalariamento. Revista Serviço Social \& Saúde. UNICAMP Campinas, v. IX, n. 9, Jul. 2010
} 
O modelo fordista de regulação é questionado e as empresas passam a considerar cada vez mais o planejamento estratégico como administração estratégica implicando um projeto de restruturação e reengenharia da empresa num mundo de novas tecnologias da informação (informática) e da produção (robô, controle mecânico). A produção em cadeia e em série passa a ser substituída pela produção em grupo ou em equipe. Nesse processo, ganha ênfase a mobilização de recursos e potencialidades internas da empresa, principalmente de seu pessoal como elemento estratégico de enfrentamento da competitividade na perspectiva de "valorização do cliente". A chamada "qualidade total" parece ser um paradigma que orienta essas mudanças, embora o conceito esteja pleno de ambigüidades (TURCHI,1997), passando de um conceito de adequação às especificações do projeto (anos 30) para adequação ao uso, "às necessidades do cliente". A qualidade não se define mais na fase da inspeção mas em todo o processo, inclusive na definição dos prazos comando-entrega, "just in time".

O Fundo Monetário Internacional (FMI) ainda dita ou reedita as regras do neoliberalismo: desestatização, privatização para estimular o "livre" mercado, estabilização com altas taxas de juros para "atrair capitais" (especulativos, não se diz), abertura comercial para as importações (não se fala muito das proteções a certos mercados e produtos, exercidas pelos países dominantes), controle do déficit (para pagar dívidas impagáveis). O círculo vicioso de aumento dos juros-aumento da dívidapagamento dos juros-aumento dos juros é um processo de crescimento do buraco financeiro da dívida e não de saneamento do déficit.

Bruno (1997) destaca que os Estados nacionais perderam poder de decisão, mas reagem diferentemente diante das crises na busca de legitimação e de valorização do mercado interno. Se é verdade que as políticas nacionais se parecem cada vez mais entre si: corte nos gastos públicos, abertura comercial, redução de impostos para os mais 
ricos, reforma do sistema de proteção social, arrocho salarial, terceirização, privatização, elas têm conotação diferente em cada Estado, de acordo com a correlação de forças interna, às lutas sociais ${ }^{11}$, variando o processo de desresponsabilização do Estado relativamente aos direitos sociais e às práticas de gestão em parcerias com organizações não-governamentais e privadas. Diante da crise de 2009 os Estados agiram num mesmo sentido mas com ênfases diferentes para "salvar" os bancos da falência em apoio ao capital financeiro.

As mudanças políticas e as mudanças no capitalismo, que assinalamos acima, não são processos lineares, mas movimentos contraditórios que geram conflitos entre os próprios setores hegemônicos e reações e movimentos das forças subalternas. As disputas comerciais não são facilmente resolvidas no interior do $\mathrm{OMC}$, a globalização não impede que haja conflitos entre Europa, Japão e Estados Unidos e, dentro da própria Europa, entre, britânicos, franceses e alemães.

É nesse quadro que recoloca a discussão do planejamento estratégico para as empresas e para o Estado. Weihrich (1990), como vários outros analistas, assinala que o planejamento estratégico consiste em maximizar as forças internas para reduzir as ameaças externas e aproveitar as oportunidades. O conceito de estratégia é, assim, extremamente vinculado à competição internacional e nacional na complexidade da interação dos fatores situacionais. O conceito de situação está ligado a esse jogo de forças no seu ambiente de desenvolvimento.

\footnotetext{
${ }^{11}$ Veja-se o caso da França, com as greves de dezembro de 1995 e os movimentos de desempregados. Revista Serviço Social \& Saúde. UNICAMP Campinas, v. IX, n. 9, Jul. 2010
} 


\section{A GESTÃO ESTRATÉGICA DO ESTADO NA AMÉRICA LATINA}

É necessário distinguir o planejamento estratégico da gestão estratégica ou administração estratégica como assinalava Ansoff et al. (1981) relevando as questões da gestão.

Na América Latina, no âmbito estatal, é na área da saúde, em especial da saúde coletiva, que se tem discutido o planejamento estratégico. Mário Testa (1995), um dos autores reconhecidos nessa área, chama a atenção para a conformação dos atores sociais de acordo com os interesses em jogo dos sujeitos coletivos, colocando como estratégia "não a maneira de alcançar a meta, mas uma maneira de se colocar em situação de se aproximar para alcançar a meta: ganhar espaço, ganhar tempo, estabelecer condições favoráveis ao nosso próprio desempenho são algumas formulações alternativas que exemplificam a idéia de estratégia, sintetizada na excelente definição de Beaufre ${ }^{12}$ : 'a estratégia é uma manobra destinada a ganhar liberdade de ação"” (p. 1). Para isto a estratégia política (maneira de se operar no manejo do poder) deve se combinar com a técnica (poder técnico) e o administrativo nos espaços globais e setoriais. Nesse contexto surge a estratégia programática que ordena recursos sob uma coordenação administrativa e normativa (p. 74), combinando plano estratégico com plano normativo. Para ele o que torna um programa participativo é sua integração com a população (p. 78). São estratégias definidas num espaço institucional distintas daquelas definidas socialmente. Distingue, ainda, estratégia da operação, onde se imbricam

\footnotetext{
${ }^{12}$ Citado pelo autor.
} 
gestão (administrativo), prática (técnico) e direção (política). Para programarr ${ }^{13}$ serviços $^{2}$ é necessário combinar a lógica dos insumos, com a lógica de bens de capital, de pessoal, de dinheiro, de instrumentos e atividades, de gestão, de organização, de população (crescimento demográfico), de demanda ou problemas, de oferta de soluções, de mercado ou projetos, de processos. A coerência entre estratégia e lógica é "a relação entre um fenômeno material e um fenômeno conceitual, a lógica” (p. 202), o que retoma a discussão entre racionalidade substantiva e formal, que já analisamos.

Testa lembra, ainda, a relação entre o voluntarismo da estratégia e o objetivismo da lógica. Bryson e Alston (1996, p. 7) definem o processo estratégico pela iniciativa de um grupo que negocia um acordo com os mandantes (decision makers) e líderes de opinião cruciais ou chave internos (e possivelmente externos) sobre todo o processo de planejamento, a agenda e as tarefas-chave do plano. A análise situacional implica, assim, considerar os "inputs" (pessoal, capital, administração, habilidades gerenciais e técnicas, demandas dos clientes) da organização e de seu ambiente em interação para as alternativas estratégicas. Para isto pode-se usar auditorias, reuniões participativas, mas a decisão fica na alta administração. Estas propostas colocam o planejamento sob a hegemonia política dos dirigentes da empresa ou do governo que buscam articular as forças, os recursos e os colaboradores externos, assim como os recursos, as estratégias e as performances internas a partir dos mandatos e missões da organização para definir as questões estratégicas dos fins e do sucesso a ser alcançado.

É nesta perspectiva que se situa a questão da qualidade total no serviço público. Este é criticado por ausências de princípios de gestão, excesso de níveis

\footnotetext{
${ }^{13}$ Diz Testa (1995, p. 189) que a programação é a reprodução intelectual das atividades e tarefas que é preciso realizar para conseguir um resultado - um produto - previamente definido e as seqüências correspondentes. Um programa é o resultado dessa elaboração com as designações - de recursos e responsabilidades administrativas - que garantam a viabilidade da proposta.
}

Revista Serviço Social \& Saúde. UNICAMP Campinas, v. IX, n. 9, Jul. 2010 
hierárquicos, lentidão, desperdício (XAVIER, BATISTA, 1997), abrindo-se espaço para a gestão ou administração estratégica. As ONGs também são pensadas nesta perspectiva (TENÓRIO, 1997, BRYSON, 1996) a partir da definição de sua missão, de seus pontos fortes e fracos, das ameaças e oportunidades do ambiente. O processo e o resultado desse planejamento é transferir para o usuário ou para terceiros muitas tarefas que se faziam na organização com a justificativa do enxugamento, na prática trazendo demissões para muitos e requalificação para outros. Hoje, alia-se o medo com fatores motivantes, ou seja o capitalismo demite uns e qualifica outros, estrategicamente, para a competitividade. Os supermercados "pegue-pague", os "home banking", o "faça você mesmo" trazem, no seu bojo, a demissão de pessoal e, ainda, transfere ao usuário os serviços que eram feitos pelos empregados.

\section{O PED E O PROCESSO POLÍTICO DEMOCRÁTICO}

A esta prática capitalista se opõe o PED, defendendo uma perspectiva humanística uma concepção integral do ser humano nas suas relações pessoais, culturais, organizacionais. Ademar K. Sato, idealizador do PED afirma sempre: "quem executa é que deve planejar" ${ }^{, 14}$. O PED é uma proposta que se situa no contexto de um governo popular e democrático e se inscreve numa política de governo configurada, em grandes linhas no Plano de Desenvolvimento Econômico e Social (PDES) que visa revolucionar as prioridades voltando-as para os excluídos mas "não se pode revolucionar as prioridades, modificar o alvo das ações governamentais, sem transformar, simultaneamente, a forma de agir, a maneira de governar, a máquina com que se governa e se administra os interesses comuns, os instrumentos e mecanismos do poder estatal. Para que as novas prioridades prevaleçam, efetivamente, será necessário

\footnotetext{
${ }^{14}$ Notas de pesquisa, 1998, daqui em diante (NP, 1998).

Revista Serviço Social \& Saúde. UNICAMP Campinas, v. IX, n. 9, Jul. 2010
} 
criar novos instrumentos e mecanismos de poder, modernizar democraticamente a máquina de governo e, finalmente, adotar uma nova maneira de governar: transparente, eficiente e democrática” (PDES, Lei 874 de 9 de junho de 1995, p. 23).

O PED se inscreve numa estratégia política de construção do poder da base, mais que na lógica técnica de estabelecer padrões formais de ação. Ele busca articular a ação que convém com a ação coordenada pela coletivização do pensamento e da ação. É necessário considerar, como afirma Faleiros $(1997)^{15}$, que para que um ator defina e decida sua participação na disputa é preciso que tenha uma direção estratégica para seu interesse, e se tiver força e recurso vai também definir o caminho a seguir. A participação democrática é um processo conflituoso, e por isso mesmo estratégica, de construção do contra-poder pois compreende uma relação onde pode ocorrer momentos de concertação entre atores e forças, e momentos de enfrentamento. A superação do conflito depende da correlação de forças, do terreno onde se esteja dando a luta, da conjuntura e das relações simbólicas, culturais e imaginárias. Nesta ótica estratégia é instrumental e relacional ao mesmo tempo, pois valoriza o peso dos "capitais" ou capacidades de cada ator no processo democraticamente aceito e compartilhado. Quanto mais profundo o terreno do compartilhamento tanto maior serão as chances de se realizar uma coletivização ou interação coletiva.

O PED é um processo que trabalha as pré-condições da democracia e da estratégia ao possibilitar a estruturação da força e a discussão da situação problemática num processo complexo de articulação da cooperação da base e da relação com os dirigentes, sem se colocar numa posição subordinada à direção, ou de troca de favores.

Em se tratando de uma experiência instituinte, isto é de mudança e questionamento, num contexto institucionalizado, ela depende do jogo de poder interno

\footnotetext{
${ }^{15}$ Documento apresentado em Seminário do Departamento de Serviço Social/IDR em fevereiro de 1997. Revista Serviço Social \& Saúde. UNICAMP Campinas, v. IX, n. 9, Jul. 2010
} 
à própria organização, da divisão do trabalho, do poder que exercem determinadas categorias na hierarquia funcional e de quais são as relações de poder em cada nível. As lutas sindicais e políticas dos trabalhadores e suas propostas são levadas em conta no PED através da linguagem dos próprios participantes que se encontram, entretanto, sem as etiquetas organizacionais. $\mathrm{O}$ PED se opõe à manipulação dos dirigentes, e valorizando as diferenças e divergências existentes na base, busca articular ações coordenadas no presente com os recursos disponíveis, na interação coletiva e ética coresponsável num processo instituinte, mas num contexto institucionalizado.

No quadro seguinte apresentamos os traços mais significativos da proposta do PES em comparação à do PED, de acordo às dimensões analíticas definidas no capítulo 1 ( cf. FALEIROS et al., 1998).

QUADRO COMPARATIVO DO PES E DO PED, DE ACORDO COM AS CATEGORIAS DE ANÁLISE

\begin{tabular}{|c|c|c|}
\hline Categorias & PES & PED \\
\hline $\begin{array}{l}\text { Ética } \\
\text { e } \\
\text { valores }\end{array}$ & $\begin{array}{l}\text { Segundo Matus "o método PES } \\
\text { qualifica a gestão do governo } \\
\text { segundo os resultados e as condições } \\
\text { fora de alcance do ator (variantes) } \\
\text { nas quais os resultados são } \\
\text { alcançados". O balanço de gestão } \\
\text { política sintetiza os resultados no } \\
\text { âmbito específico que responde às } \\
\text { demandas políticas dos atores sociais } \\
\text { e da população em geral. O balanço } \\
\text { macro-econômico registra custos e } \\
\text { benefícios, vendo-se a eficácia } \\
\text { macroeconômica. O balanço de } \\
\text { intercâmbio de problemas específicos } \\
\text { visa manter os "placares" dos } \\
\text { problemas dentro de metas aceitáveis } \\
\text { em relação à situação anterior. "A } \\
\text { cidadania é o juiz que avalia no } \\
\text { presente o impacto da gestão } \\
\text { pública" (1993, p. } 30 \text {-1) }\end{array}$ & $\begin{array}{l}\text { Os princípios éticos do PED são o } \\
\text { PRINCÍPIO DEMOCRÁTICO que } \\
\text { compreende participação, } \\
\text { igualdade, respeito; o PRINCÍPIO } \\
\text { DA EFICIÊNCIA que implica } \\
\text { precisão, responsabilidade e bom } \\
\text { senso; o PRINCÍPIO DO PRAZER } \\
\text { E DA ALEGRIA que compreende } \\
\text { beleza, ritmo e criatividade. O PED } \\
\text { valoriza tanto a eficiência como a } \\
\text { participação, a igualdade e o } \\
\text { respeito, e o processo de caminhar } \\
\text { dos próprios sujeitos envolvidos no } \\
\text { seu ritmo e na beleza de seus } \\
\text { passos. } \\
\text { O PED se inscreve numa proposta } \\
\text { de gestão democrática e popular do } \\
\text { Estado e do governo. Os princípios } \\
\text { devem ser entendidos nessa } \\
\text { perspectiva de construção do poder } \\
\text { popular. }\end{array}$ \\
\hline
\end{tabular}




\begin{tabular}{|c|c|c|}
\hline Categorias & PES & PED \\
\hline $\begin{array}{l}\text { Relação } \\
\text { Estado } \\
\text { /Sociedade }\end{array}$ & $\begin{array}{l}\text { O governo deve compensar os } \\
\text { fracassos na solução de problemas } \\
\text { com ação política, para não perder } \\
\text { seu capital político. "A pior gestão } \\
\text { política é aquela que consome o } \\
\text { capital político do governante sem } \\
\text { atingir os resultados proclamados } \\
\text { e perseguidos" (p. 34). Deve-se } \\
\text { manter o equilíbrio de intercâmbio } \\
\text { entre o governo e a população, } \\
\text { "buscando-se que a população } \\
\text { sempre esteja em dívida para com } \\
\text { o governante e não o contrário" } \\
\text { (p. 39). O governo é visto acima } \\
\text { dos interesses das classes. }\end{array}$ & $\begin{array}{l}\text { A população é credora do governo } \\
\text { e não devedora, pois deve-se servir } \\
\text { ao público e não se servir do } \\
\text { público. A construção da cidadania } \\
\text { é um processo articulado com o } \\
\text { desenvolvimento da democracia e } \\
\text { da participação e com a defesa dos } \\
\text { direitos sociais, políticos e civis. O } \\
\text { Estado é visto como garantidor de } \\
\text { direitos e como correlação de } \\
\text { forças. A gestão democrática } \\
\text { compartilha decisões, } \\
\text { contrariamente à gestão } \\
\text { tecnocrática e autoritária. }\end{array}$ \\
\hline
\end{tabular}

\begin{tabular}{|l|l|l|}
\hline \multicolumn{1}{|c|}{ Categorias } & \multicolumn{1}{|c|}{ PES } & \multicolumn{1}{|c|}{ PED } \\
\hline dinâmica & $\begin{array}{l}\text { "A qualidade da gestão de um } \\
\text { governante dependerá, se } \\
\text { descartarmos a influência do } \\
\text { organizações }\end{array}$ & $\begin{array}{l}\text { Enfase no processo coletivo, } \\
\text { progressivo, construtivo de } \\
\text { decisões em que as decisões são } \\
\text { tomadas pela base. }\end{array}$ \\
& $\begin{array}{l}\text { que deve agir, depende } \\
\text { essencialmente de: a) capacidade } \\
\text { pessoal de governo, ou seja, do } \\
\text { capital intelectual ao qual deve } \\
\text { recorrer durante o período de } \\
\text { mandato; b) a capacidade } \\
\text { institucional de governo, ou seja, } \\
\text { o capital organizacional que estará } \\
\text { a seu dispor" (1997, p. 311). Esta } \\
\text { significa o processamento } \\
\text { tecnopolítico dos problemas } \\
\text { cotidianos, ou seja “evitar os } \\
\text { incompetentes e a } \\
\text { incompetência", reduzindo-se a } \\
\text { gestão pública ao "discurso e ação } \\
\text { competente" para azeitar a } \\
\text { "maquinária do governo", para } \\
\text { que as ações correspondam às } \\
\text { decisões e as decisões } \\
\text { correspondam às propostas", } \\
\text { concentrando-se em agenda, } \\
\text { cobrança e gerência (1997, p. } \\
\text { 318), com ênfase no entorno do } \\
\text { governante para que se concentre } \\
\text { nas decisões críticas. }\end{array}$ & \\
& \\
& \\
\hline
\end{tabular}




\begin{tabular}{|c|c|c|}
\hline Categorias & PES & PED \\
\hline $\begin{array}{l}\text { Democracia } \\
\text { e } \\
\text { participação, } \\
\text { tecnocracia }\end{array}$ & $\begin{array}{l}\text { O planejamento está centrado na UPT } \\
\text { (Unidade de Processamento } \\
\text { Tecnopolítico) que monitora o } \\
\text { dirigente e examina, acompanha e } \\
\text { cobra os planejamentos parciais e } \\
\text { setoriais com pessoal capacitado para } \\
\text { enfrentamento das crises. São } \\
\text { necessários cientistas e políticos de } \\
\text { altos vôos para que se selecionem a } \\
\text { partir da direcionalidade, as missões } \\
\text { que a organização deve cumprir (1997, } \\
\text { p. } 340 \text { et seq.). As relações } \\
\text { institucionais são: a) paralelas; b) de } \\
\text { dependência hierárquica; c) de alta } \\
\text { direção e d) de gerência. }\end{array}$ & $\begin{array}{l}\text { A missão da organização é } \\
\text { contraditoriamente vista no } \\
\text { conflito de valores dos } \\
\text { participantes que trabalham os } \\
\text { valores mais gerais e aqueles que } \\
\text { orientam seu dia a dia e se define } \\
\text { pelo compartilhamento } \\
\text { democrático, tendo como ponto de } \\
\text { partida a cidadania como relação } \\
\text { fundamental e fundadora da } \\
\text { missão pública, que define o } \\
\text { próprio processo de participação. } \\
\text { A participação é, por sua vez, } \\
\text { fundadora da cidadania, pois traz } \\
\text { no seu bojo a força da divergência } \\
\text { e da tolerância, da solução dos } \\
\text { conflitos pela maioria, da } \\
\text { organização e da pressão e } \\
\text { negociação. }\end{array}$ \\
\hline
\end{tabular}

\begin{tabular}{|c|c|c|}
\hline Categorias & PES & PED \\
\hline $\begin{array}{l}\text { Construção } \\
\text { do sujeito } \\
\text { como } \\
\text { indivíduo } \\
\text { e do sujeito } \\
\text { coletivo }\end{array}$ & & $\begin{array}{l}\text { É essencial o exercício ativo dos } \\
\text { direitos individuais e sociais, a } \\
\text { construção da união e do } \\
\text { compromisso e do engajamento } \\
\text { na dinâmica relacional entre } \\
\text { atores em presença. } \\
\text { A busca do prazer e da alegria não } \\
\text { estão separadas da busca da } \\
\text { eficiência, pois busca-se agir } \\
\text { "com o que se gosta" para a } \\
\text { realização da tarefa e auto- } \\
\text { realização do sujeito. Não se } \\
\text { separa a objetividade da } \\
\text { subjetividade, com ênfase na } \\
\text { inter-subjetividade. }\end{array}$ \\
\hline
\end{tabular}

\begin{tabular}{|c|c|c|}
\hline Categorias & PES & PED \\
\hline $\begin{array}{l}\text { Racionalidade } \\
\text { e metodologia } \\
\text { do } \\
\text { planejamento }\end{array}$ & $\begin{array}{l}\text { "O centro da planificação estratégico- } \\
\text { situacional são os problemas. A } \\
\text { interação entre problemas se precisa } \\
\text { em causas e conseqüências (1993a, } \\
\text { p.17). Assim, a lógica dominante do } \\
\text { PES é a de causa/efeito. Os problemas } \\
\text { são "deficiências presentes detectadas } \\
\text { na observação" (p.18), ou seja na } \\
\text { perspectiva de alguém que observa, }\end{array}$ & $\begin{array}{l}\text { O PED está centrado na produção } \\
\text { coletiva de conhecimentos a partir } \\
\text { das dificuldades, do contexto, da } \\
\text { conjuntura, da organização, da } \\
\text { ética. O "problema" - dificuldade } \\
\text { é visto na perspectiva das } \\
\text { necessidades sociais em suas } \\
\text { relações interdependentes e não } \\
\text { como um projeto de governo. O }\end{array}$ \\
\hline
\end{tabular}




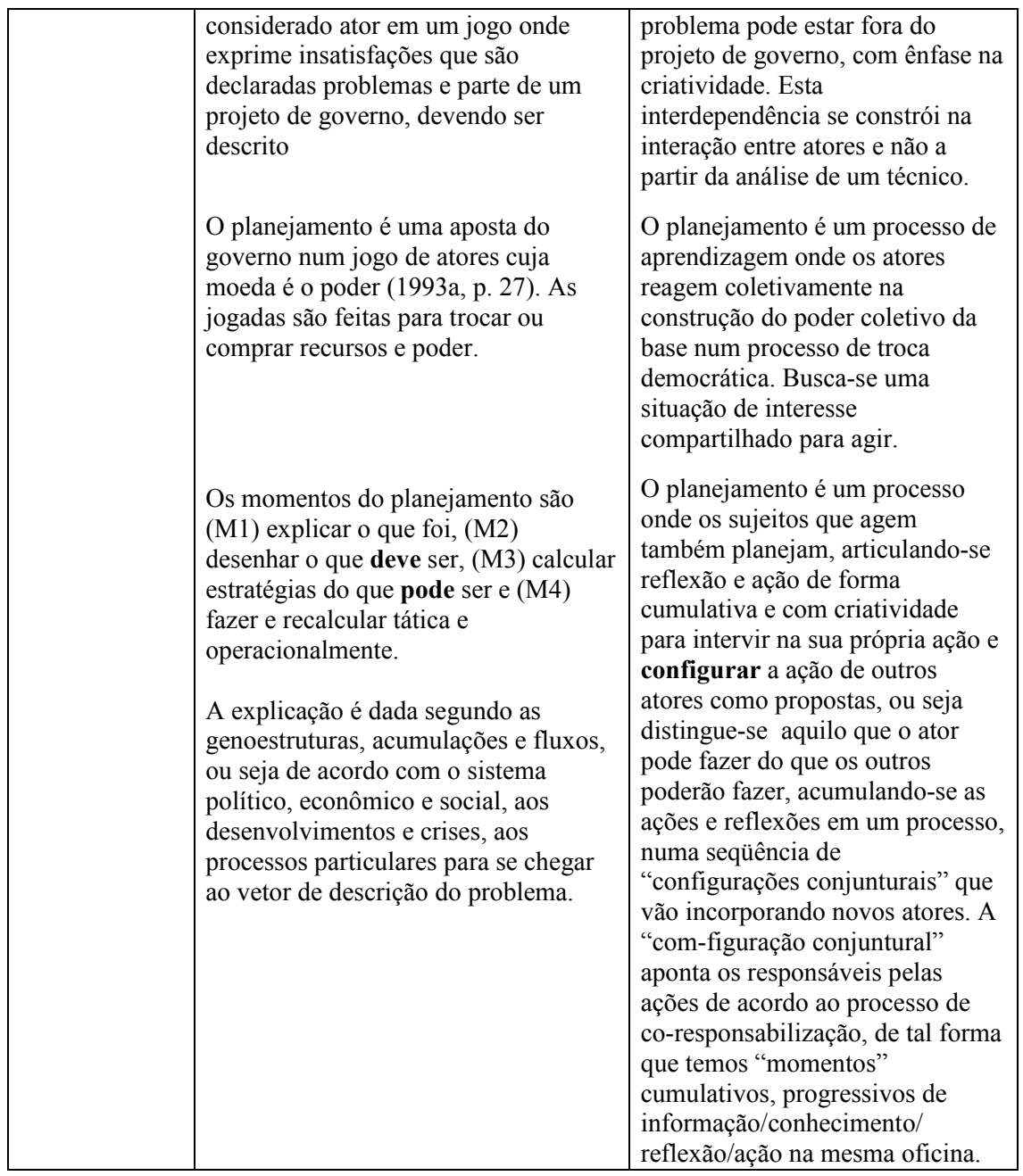

\begin{tabular}{|c|c|c|}
\hline Categorias & PES & PED \\
\hline $\begin{array}{l}\text { Ideologia } \\
\text { e concepção } \\
\text { da história }\end{array}$ & $\begin{array}{l}\text { O fundamental para se planejar é criar } \\
\text { "sistemas organizacionais de alta } \\
\text { responsabilidade", evitando-se o } \\
\text { tecnocratismo e a improvisação, pois o } \\
\text { "planejamento é concebido para servir } \\
\text { o dirigente político que tenta enxergar } \\
\text { além da curva do futuro" (1997, p. } \\
\text { 202). O planejamento está a serviço da } \\
\text { alta direção para aumentar a }\end{array}$ & $\begin{array}{l}\text { O PED adota uma visão do ser } \\
\text { humano humanística e integral, } \\
\text { considerando as condições } \\
\text { objetivas, a inter-subjetividade e a } \\
\text { subjetividade. } \\
\text { Busca o resgate da cidadania, } \\
\text { articulando a ação estratégica com } \\
\text { a democracia, na construção da } \\
\text { aprendizagem coletiva da razão }\end{array}$ \\
\hline
\end{tabular}




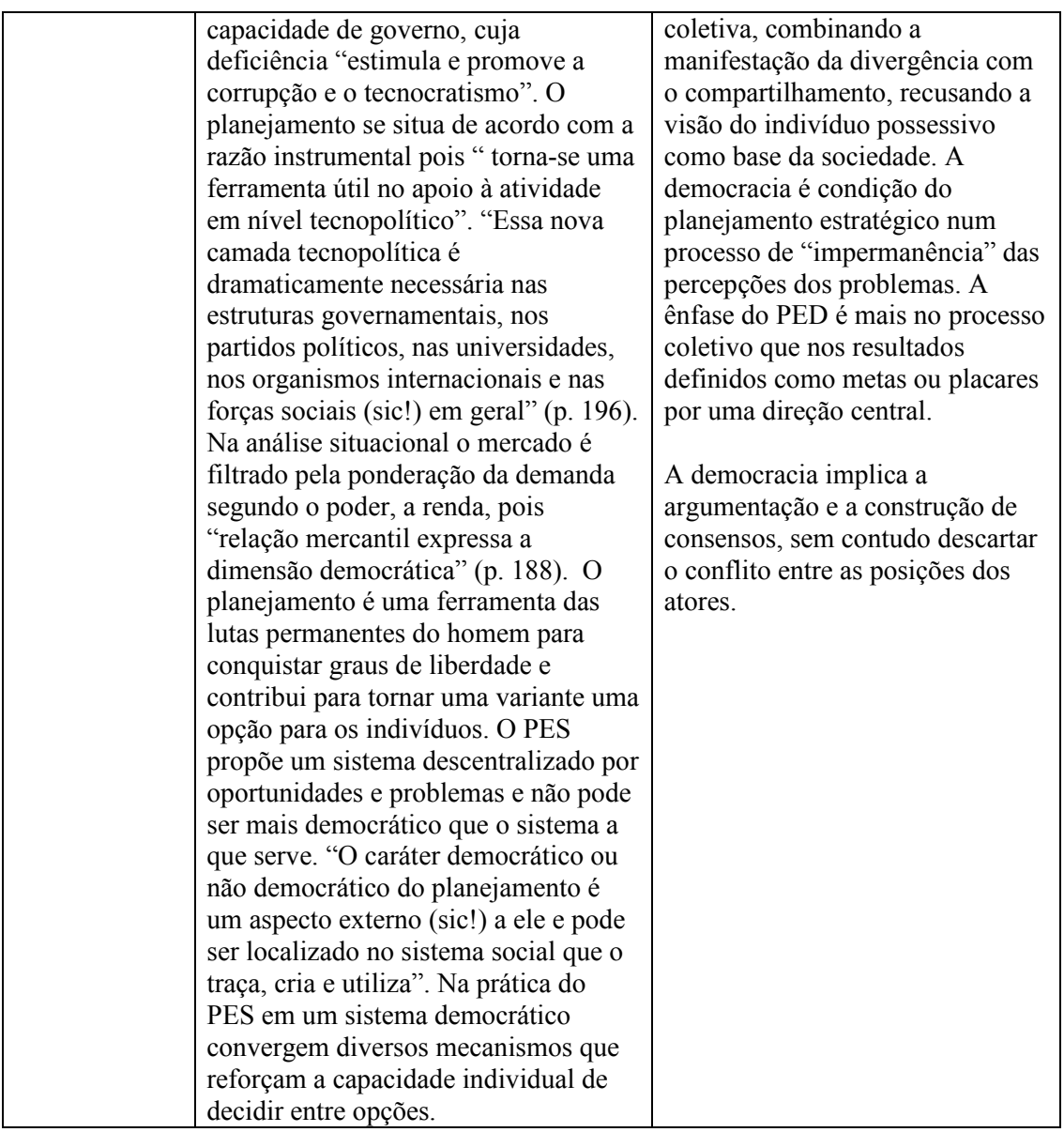

\section{CONSIDERAÇÕES FINAIS}

No desenvolvimento do trabalho já fomos assinalando a relação entre os contextos históricos e os processos de planejamento. A chamada racionalidade do planejamento é uma forma de justificar as propostas do bloco no poder seja para montar a legitimação seja para montar o processo de acumulação. São discursos de articulação entre o econômico e o político. 
A relação entre estratégia e democracia está presente em tentativas de planos estatais como no Chile de Allende, mas principalmente em grupos ou áreas limitadas onde se consegue o envolvimento dos participantes nas decisões tomadas. Essa articulação também depende do contexto político democrático onde se possa abrir espaços para decisão mesmo em setores limitados como aconteceu com as experiências de Orçamento Participativo em certos governos do PT. Uma parcela do orçamento pode ser influenciada por decisões da população, mas deve ser re-discutida quando do planejamento global.

As diferenças entre o PES e o PED foram trabalhadas conforme certas categorias analíticas e verifica-se que as categorias de ética e valores, relação estado/sociedade/economia, democracia e participação e poder, cultura, racionalidade, ideologia, concepções da história, educação e percepção dos sujeitos são fundamentais para o processo de planejamento que se inscreve numa dinâmica de correlação de forças.

\begin{abstract}
This article deals with proposals and the social economic planning process, considering that the planning doesn't constitute a neutral technology but a conflict arena between technicians and politicians, State and Society, capital accumulation and political legitimation. It analyses the diversity of planning forms in the historical contexts of the capitalism and the relation between strategy, democracy and centralized political power. It concludes that the so called rationality of the planning process and the relation between strategy and democracy are articulated to the social forces and to the political context.
\end{abstract}

KEYWORDS: Social Economic Planning, Strategy, Democracy, Political Power 


\section{REFERÊNCIAS BIBLIOGRÁFICAS}

ANDER-EGG, E. Metodología del trabajo social. Barcelona: El Ateneo, 1982.

ANSOFF, H. I. et al. Do Planejamento Estratégico à Administração Estratégica.

São Paulo: Atlas, 1981.

BATTERSBY, A. Planificación y programación de proyectos complejos. Barcelona: Ariel, 1967.

BRUNO, L. Poder e administração no capitalismo contemporâneo. In: OLIVEIRA, D.

A. (Org.) Gestão Democrática da Educação. Petrópolis: Vozes, 1997.

BRYSON, J. M., ALSTON, F.K. Creating and implementing your strategic plan. San Francisco: Jossey-Bass Publishers, 1996.

CAPITANI, G.R.S. PED: Planejamento Estratégico democrático ou processo educacional democrático? Brasília: UnB. Dissertação de Mestrado. Faculdade de Educação, 2002

CASTRO, J. A. Dinâmica política associada ao processo de planejamento e gestão estatal. Brasília: CENDEC, mimeografado. 1995.

CEPAL. El pensamiento de la CEPAL. Santiago: Editorial Universitária, 1969.

COHEN, E, FRANCO, R. Gestão Social: como obter eficiência e impacto nas políticas sociais? Brasília: ENAP, 2007.

DANTAS, J.L. A teoria metodológica do Serviço Social. Documento de Teresópolis. Suplemento de Debates Sociais, Rio de Janeiro, n.4, $5^{\mathrm{a}}$ edição, 1978, p.61-124.

FAlEIROS, V.P. et al. Que é o PED? Relatório Final de Pesquisa. Brasília: GDFSecretaria de Administração- Instituto de Desenvolvimento e Recursos Humanos, 1998.

FALEIROS, V.P. Estratégias em Serviço Social. São Paulo: Cortez, 1997.

FONDO EDITORIAL ALTADIR. Método MAPP - Método Altadir de Planificación

Popular. Santa Fé de Bogotá: Fondo Editorial Altadir, 1994. 
FRIEDMANN, J.R.P. Introdução ao Planejamento Democrático. Rio de Janeiro: Fundação Getúlio Vargas, 1959.

FRIEDMANN, J. Planejamento na América Latina: da ilusão tecnocrática à democracia aberta. In: CENDEC. Seminário Internacional. Estado e planejamento. Sonhos e realidade. Brasília: CENDEC, 1988, pp. 161-86.

GRAMSCI, A. Maquiavel, a política e o Estado moderno. Rio de Janeiro: Civilização Brasileira, 1980.

HELOANI, R. Organização do trabalho e administração. Uma visão interdisciplinar. São Paulo: Cortez Editora, 1994.

IANNI, O. Estado e planejamento econômico no Brasil (1930-1970). Rio de Janeiro: Civilização Brasileira, 1977.

ILPES. Discusiones sobre planificación. México: Siglo XXI, 1966.

ILPES. Teoria y práctica de la planificación en América Latina. Santiago: CEPAL/ILPES, 1980.

LIMA, B. Contribución a la metodología del trabajo social. Caracas: Colegio Universitario de Caracas, 1974.

LOTERO, J. El pensamiento cepalino: estructuralismo y regulación del desarrollo. In: Lecturas de Economia (27): 139-61, Medellin, Sep/Dici,1988.

MATUS, C. 1997. Chipanzé, Maquiavel e Ghandi - Estratégias políticas. São Paulo: FUNDAP, 1996.

MATUS, C. Adeus Senhor Presidente: Governantes Governados. São Paulo: FUNDAP, 1997.

MATUS, C. 1993 (a) Política, planejamento e governo. Brasília, IPEA, ( 2 vol.)

MATUS, C. 1972 Estratégia y plan. Santiago, Editorial Universitária, 
MAUTNER, G. Planificación y presupuesto por programas. México: Siglo XXI,1969.

NOVICK, D. La programmation budgétaire, instrument de planification à long terme. In : JANTSH, E. Prospective et politique. Paris: OCDE, 1969, pp. 243-57.

OZBEKHAN, H. 1969 Vers une théorie générale de la planification. In: JANTSH, E. Prospective et politique. Paris: OCDE, 1969, pp.43-147.

PENNA, P.C.O.1963 A necessidade do planejamento. In: RIVERA, F. Xavier Uribe (Org.) Planejamento e programação em saúde. São Paulo: Cortez, 1989.

SILVEIRA JÚNIOR, A, VIVACQUA, G.A. Planejamento estratégico como instrumento de mudança organizacional. Brasília: Editora da UnB, 1996.

TENÓRIO, F.G. (Org.) Gestão de ONGs. Rio de Janeiro: FGV, 1997.

TESTA, M. Pensamento estratégico e lógica de programação. Rio de Janeiro: Hucitec, 1995.

VUSKOVIC, P. La experiencia chilena - problemas económicos. In: BASSO, L. et alii. Transición al socialismo y experiencia chilena. Santiago: CESO/CEREN, 1972.

WEIHRICH, H. The TOWS Matrix: a tool for situational analysis. In: DYSON, R.G. Strategic Planning Models and techiniques. New York, John Wiley \& Sons. 1990, p.17-36.

XAVIER, A.C.R., BATISTA, F.F. Um novo paradigma de gestão ou mais um programa de qualidade? A experiência do Hospital das Clínicas de Porto Alegre. Brasília: IPEA, 1997. Texto para Discussão nº 487.

ZOPP. Iniciação ao Método. Frankfurt am Main - GTZ, s./d. 